MATEC Web of Conferences 51, 01009 (2016)

DOI: $10.1051 /$ matecconf/20165101009

(C) Owned by the authors, published by EDP Sciences, 2016

\title{
Work Hours And Sorting Balancing Study of One Auto Mixed Line
}

\author{
Cao Shouqi, Chen Ying ${ }^{a}$ and Chen Chengming \\ College of Engineering Science and Technology, Shanghai Ocean University, Shanghai, China
}

\begin{abstract}
To deal with the former sub-frame assembling mixed line balance of One Automotive Industry Corporation, the study has used the methods from Industrial Engineering such as ECRS and motion analysis principles to find the problem factors and has improved the stations and their work hours and decreased the number of workers to reduce the personnel cost. Meanwhile it has used FLEXSIM to simulate and got the best production scheduling plan to improve the production efficiency.
\end{abstract}

\section{Introduction}

Mixed line production has a strong development since 1980s and it is mostly used in aircraft and automobile manufacturing. And the automobile production mode has changed to lean production of small amount and multispecies from mass amount and single species, then the study of mixed line balance consists of the work hour balance study and multispecies sorting balance study.[1]

This paper is based on Industrial Engineering theories and FLEXSIM simulating to analyze the balance problems of sub-frame mixed assembling production line. It aims at to reduce the work hours of every worker and get a best sorting plan to improve the whole production line.

\section{Mixed Line Production and Balance Study Overview}

\subsection{Front Subframe Mixed Line Production Overview}

Front sub-frame is one part of underpan and is the constituent part of front back-axle. There are two types productions named as A and B and 13 stations on this assemble line. Through the analysis of relevant videos and spot observation, there are some main problems that influenced the production efficiency such as follows:

(1) Work hours load imbalance

Some workers finish their work quickly when the other workers still work at the same time.

(2)Motorcycle type production ratio is not the best

Type $\mathrm{A}$ is assembled on station 1 for a long time, then the next type must wait on station 2 with not being assembled, so should choose one sorting plan which is the best and meeting the real situation to decrease waiting time and avoid overload to increase efficiency.

\footnotetext{
${ }^{a}$ Corresponding author : cy07120810@163.com
} 


\subsection{Balance study methods overview}

\subsubsection{Industrial Engineering theories}

For the work hours balance study, there are some methods as follows to solve the production balance in Industrial Engineering:

(1) ECRS analysis theory

This theory mainly aims at work allocation for each worker during the operating. Eliminate the not necessary motions and combine two or more easy motions and rearrange the motions order and simplify the complicated motion.

(2)Ten principles of motion analysis

The details are as follows:

1) The motions on both hands should be the same time and symmetrical.

2) Body movements should be the lowest level and achieve satisfaction.

3) Use objects' kinetic energy;

4) Tools and materials should be put close to workers and sorted in the best work order.

5) Use elements' and materials' self-weight to workers (Gravity feed).

6) Should have proper lighting equipments and the height of workbench and chairs should be good to workers.

7) Delete hands motions in possible and replaced by fixtures or feet tools, then workers can be relaxed.

8) Should combine two or more tools be one if possible.

9) The work load should be balanced; Let workers do less if possible.

10) Tools and materials should be put in the work stations in advance. [2-4]

\subsubsection{Balance calculation formula}

The balance rate computational formula as follow:

$$
\text { Balance rate } \eta=1-\frac{N * C-t \text { 总 }}{N * C} * 100 \%
$$

In the formula, $t$ 总 is the total assembled time, $N$ is the number of stations, $C$ is operating beat.

\subsubsection{FLEXSIM simulating}

FLEXSIM is a software developed by a American company. Some researchers used it to simulate the manufacturing process and count the whole assemble time to analyze through model the production line and set the corresponding parameters.[5]

\section{Mixed Line Balance Study of Front Subframe}

For the work hours balance study, this paper set the product beat as $A=66 \mathrm{~s} /$ stage and $\mathrm{B}=60 \mathrm{~s} / \mathrm{stage}$ and each station has one worker and every two stations cannot start at the same time and if the last station's work is not finished, then the next station will not begin.

\subsection{Work hours balance study}

\subsubsection{Initial work hours data}

Table1 is the operating time of A and B: because of every worker's different proficiency and some others elements, so if the station work hours has \pm 10 s different with the beat, it is acceptable. If the work hour is over or under the beat for 10 s or more, it should be considered to be improved. 
Table1. A and B work hours

\begin{tabular}{|c|c|c|}
\hline Station & A's work hour(s) & B's work hour(s) \\
\hline 1 & 54.20 & 63.20 \\
\hline 2 & 61.06 & 62.83 \\
\hline 3 & 80.81 & 50.92 \\
\hline 4 & 63.07 & 45.91 \\
\hline 5 & 70.47 & 73.90 \\
\hline 6 & 62.97 & 59.01 \\
\hline 7 & 67.59 & 74.31 \\
\hline 8 & 74.16 & 54.51 \\
\hline 9 & 64.92 & 67.11 \\
\hline 10 & 68.07 & 62.45 \\
\hline 11 & 53.25 & 58.08 \\
\hline 12 & 78.56 & 64.69 \\
\hline 13 & 64.04 & 48.16 \\
\hline Total & 863.17 & 785.08 \\
\hline
\end{tabular}

According to the beat, compare the station work hour with their type's beat and calculate the balance rate as follows:

(1) During A's processing, the time of station 3 and station 12 are over the beat like $13 \mathrm{~s}$ and the time of station 1 and station 11 are under the beat like 12s. Station 1 and 13 are adjacent and so station 11 and 12 do, so need adjust these stations' work and facility layout.

(2) During B's processing, operating time of station 5 and 7 and 9 are all over the operating beat and they are choke point stations that need be improved, meanwhile, the operating time of station 4 and 13 are smaller and also need get reassignment.

(3) Initial balance rate

Put the work hour data of $\mathrm{A}$ and $\mathrm{B}$, then get their balance rate as follows:

Balance rate of $\mathrm{A}: \eta_{A I}=1-\frac{13 * 66-863.17}{13 * 66} * 100 \%=100.6 \%>100 \%$ 。

Balance rate of B: $\eta_{B I}=1-\frac{13 * 60-785.08}{13 * 60} * 100 \%=100.65 \%>100 \%$ 。

From the result, both A and B's work hours balance rate is not normal. Then analyze each station's process and find the problem and optimize based on the Industrial Engineering principles.

\subsubsection{The analysis of productions' work hours}

Because every station has a lot process and the methods for improvement is the same, so take the improvement of A's station 11 and 12 for example.

Table 2. Process of A's station 12

\begin{tabular}{|l|c|}
\hline \multicolumn{1}{|c|}{ Work content } & Time(s) \\
\hline 1. Get material a & 37.41 \\
\hline $\begin{array}{l}\text { 2. Tie up the power steering machine oil filling pipe to power } \\
\text { steering pump }\end{array}$ & 3.60 \\
\hline 3. Get material b & 6.11 \\
\hline 4. Install inlet oil pipe to storage tank assembly & 2.44 \\
\hline 5. Install power steering oil pot to power steering pump & 4.79 \\
\hline 6.Connect air conditioning evaporation tube and radiator & 6.60 \\
\hline 7. Tidy engine lines & 3.80 \\
\hline 8. Install quick release buckle to sub-frame & 5.16 \\
\hline 9. Self-check & 8.65 \\
\hline
\end{tabular}

From Table2, this station's time of getting materials is $37.41 \mathrm{~s}$ and close to $1 / 2$ of all time. So the distance of materials and station should be adjusted and decrease the time. The details are as follows: 
Table 3. Some operation details of station 12

\begin{tabular}{|c|c|c|c|c|}
\hline Get materials & Objects & Time(s) & $\begin{array}{c}\text { Left hand operating } \\
\text { state(0 is operating/1 } \\
\text { is waiting) }\end{array}$ & $\begin{array}{c}\text { Right hand } \\
\text { operating state(0 is } \\
\text { operating/1 is } \\
\text { waiting) }\end{array}$ \\
\hline Get material 1 & Pneumatic gun & 1.29 & 1 & 0 \\
\hline Get material 3 & $\begin{array}{c}\text { Steering liquid } \\
\text { storage pot to } \\
\text { binning pump fuel } \\
\text { sucking pipe }\end{array}$ & 1.80 & 0 & 1 \\
\hline Put down material 4 & Cock & 1.00 & 0 & 0 \\
\hline Get material 8 & Clip & 5.03 & 0 & 0 \\
\hline Get material 9 & nipper & 1.11 & 0 & 0 \\
\hline Put down material 10 & nipper & 0.49 & 1 & 1 \\
\hline Get material 11 & Component & 0.84 & 0 & 0 \\
\hline Get material 16 & Nut & 1.69 & 1 & 1 \\
\hline Get material 17 & Line assembly & 2.16 & 0 & 0 \\
\hline Get material 18 & Lube & 0.92 & 0 & 0 \\
\hline Put down material 22 & Electric gun & 0.84 & 1 & 1 \\
\hline Get material 23 & White paint pen & 1.85 & 0 & \\
\hline
\end{tabular}

A. Analyze Table3's data and get the conclusion: the motions about getting material 3 and 4, because of the left hand waiting of motion 3 and both hands can operate together, so can integrate their time and the final time is 1.80s; Same to above, combine the motion 8 and 9 and the final time is 5.03s. And then use the same method and combine the motion 10 and 11 and the final time is $0.84 \mathrm{~s}$. As the same, combine the motion 16 and 17 and the final time is $2.16 \mathrm{~s}$ and combine the motions of putting down material 22 and 23 and the final time is $1.85 \mathrm{~s}$. After all the improvement, the all operating time of station 12 is $73.43 \mathrm{~s}$.

B. Because the operating time of station 11 is short and the residual quantity with the beat is $12 \mathrm{~s}$, so transfer second process of station 12 to the worker of station 11, then the operating time of station 12 changes to $66.51 \mathrm{~s}$ and time of station 11 changes to $60.17 \mathrm{~s}$.

As well, use the same methods to improve the other stations of type A and B that need improved.

\subsubsection{Stations' work hours balance analysis after improved}

Calculate and adjust the process and facility layout towards different motorcycle types again and again, then get the total assembled work hours after improvement as A is $781.64 \mathrm{~s}$ and B is $708.98 \mathrm{~s}$.

Through the formula, the after work hour balance rate of type A and B are as follows:

A's after balance rate: $\eta_{A 2}=98.69 \%$

B's after balance rate: $\eta_{B 2}=98.47 \%$

\subsubsection{Station work hour balance study conclusion}

The conclusion is that has used the Industrial Engineering methods to adjust and improve station process and decreased the number of stations and decrease the personnel cost and the station work hours are all close to the beat.

\subsection{Productions process sorting balance study}

This paper assumes that front sub-frame assembled line is stable and process continuously, the date need for type A and B of the market are 270 stages and 180 stages and the day work hour is $8 \mathrm{~h}$. 
In the mixed line process, the mixed beat

$$
r=\text { Work hours / Sum of all type needs }
$$

According to the above assumption, this mixed beat $r=\frac{8 * 60 * 60 s}{270+180}=64 \mathrm{~s} /$ Stage .

\subsubsection{Sorting combinatory analysis}

All the sum needs of type A and B is 450 stages and use the cyclic sorting method to find the minimum cell of two types' needs ratio, according to the number in the minimum cell to sort and then recycle it. Under this assumption, the number of sorting combinatory is $n=\frac{5 * 4 * 3 * 2 * 1}{(3 * 2 * 1) *(2 * 1)}=10$.

\subsubsection{Sorting simulation analysis}

There is 10 different sorting plans and if calculate one by one will be a huge work. So it uses FLEXSIM to simulate. Set the objective function $f=\sum_{i=1}^{N} I D L E_{i}+\sum_{i=1}^{N} O V E R_{i}$ and $I D L E_{i}$ is the waiting time, $O V E R_{i}$ is overload time. The sorting plan with the minimum $f$ is the best.

(1) Build simulation model

According to entities in FLEXSIM, build the model for simulation as the follow Figure1:

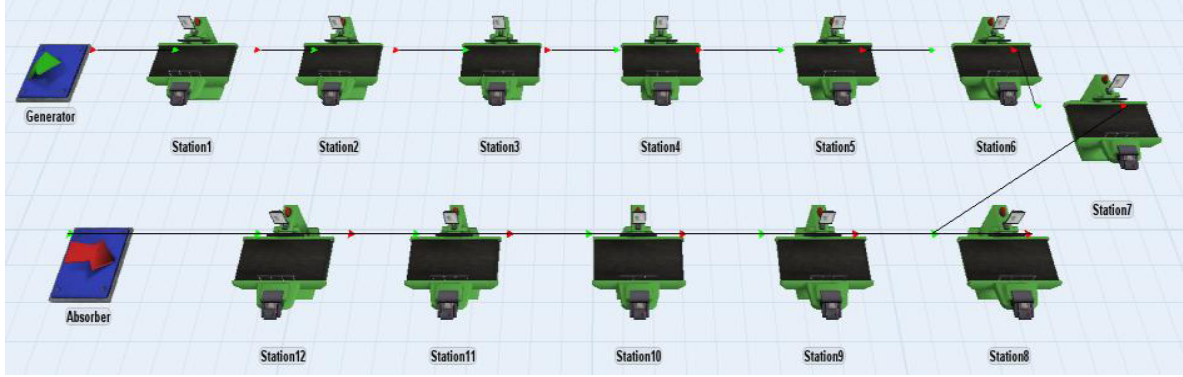

Figure1. Model building

(2) Sorting combinatory parameter determination

Set the relevant parameter in FLEXSIM according to each type's beat and every sorting combinatory. During the model building, generator 3 is the output pot of all the processed products. And input every arrival's time when the arrival method is "Arrival time schedule"

(3) Operating time parameter determination

Set "Deal depends on the type of entities" and set every generator's case and face to the real.

(4) Set the simulation time and get the final conclusion.

\subsubsection{Choose result of sorting plans}

According to simulation analysis through FLEXSIM, get every objective function value as follows:

Table 4. Every sorting plan's function value

\begin{tabular}{|c|c|}
\hline Sorting plan & Objective function $\boldsymbol{f}$ \\
\hline 12211 & 25721.31 \\
\hline 21112 & 25655.72 \\
\hline 21121 & 26305.08 \\
\hline 21211 & 26313.52 \\
\hline 22111 & 25664.18 \\
\hline 11122 & 25686.35 \\
\hline 11212 & 26313.18 \\
\hline
\end{tabular}




\begin{tabular}{|c|c|}
\hline 11221 & 25708.47 \\
\hline 12112 & 26342.21 \\
\hline 12121 & 26348.44 \\
\hline
\end{tabular}

From Table 4, the plan which has the minimum objective function value is 2-1-1-1-2 and choose this plan can get rid of long waiting time or high overload, then improve the work self-use ratio and decrease the time cost and then improve the production efficiency.

\section{Conclusion}

After the Industrial Engineering methods use and simulating the production sorting with FLEXSIM. The results are:

(1) A's balance rate had changed to $98.69 \%$ from the first $100.6 \%$, B's balance rate had changed to $98.47 \%$ from the first $100.65 \%$.

(2) The number of stations had changed to 12 from 13, the workers had been decreased and then the cost of the workers and time were both decreased and improved the worker use ratio.

(3) Through the simulation with FLEXSIM, set the parameter function and got a best plan that had fewer waiting and overload time.

\section{References}

1. X.Y.WU. Study of assembling production balance [D].Shanghai: Shanghai Jiaotong University(2007).

2. S.P YI, F.GUO. Basic Industrial Engineering [M].Beijing: China Machine Press(2011).

3. F.GUO, K.M.ZHANG. Industrial Engineering and Management, 2,120 (2005).

4. R.Q.CHEN, S.H.MA. Production management [M]. Beijing:Higher Education Press(2007).

5. J.R.ZHANG. Simulation Study Based on FLEXSIM mixed flow assembly line simulation of a car [D].Shanxi: Changan University(2009). 